\title{
Lusioersily
}

\section{Computing the Spatial QRS-T Angle Using Reduced Electrocardiographic Lead Sets}

Guldenring, D., Finlay, D., Bond, RR., Kennedy, A., McLaughlin, J., Galeotti, L., \& Strauss, D. G. (2016).

Computing the Spatial QRS-T Angle Using Reduced Electrocardiographic Lead Sets. Journal of

Electrocardiology, 49(6), 794-799. https://doi.org/10.1016/j.jelectrocard.2016.07.015

Link to publication record in Ulster University Research Portal

\section{Published in:}

Journal of Electrocardiology

Publication Status:

Published (in print/issue): 01/11/2016

DOI:

10.1016/j.jelectrocard.2016.07.015

\section{Document Version}

Author Accepted version

\section{General rights}

Copyright for the publications made accessible via Ulster University's Research Portal is retained by the author(s) and / or other copyright owners and it is a condition of accessing these publications that users recognise and abide by the legal requirements associated with these rights.

\section{Take down policy}

The Research Portal is Ulster University's institutional repository that provides access to Ulster's research outputs. Every effort has been made to ensure that content in the Research Portal does not infringe any person's rights, or applicable UK laws. If you discover content in the Research Portal that you believe breaches copyright or violates any law, please contact pure-support@ulster.ac.uk. 


\section{Computing the Spatial QRS-T Angle Using Reduced Electrocardiographic Lead Sets}

Daniel Guldenringa, Dewar D. Finlaya, Raymond R. Bond ${ }^{a}$, Alan Kennedya, James McLaughlin $^{\mathrm{a}}$, Loriano Galeottib, David G. Strauss ${ }^{\mathrm{b}}$

aUlster University, Jordanstown campus, Shore Road, Newtownabbey, Co. Antrim, BT37 0QB, Northern Ireland, UK

bOffice of Science and Engineering Laboratories, CDRH, US FDA, Silver Spring, MD, USA

\section{Abstract}

The 'spatial QRS-T angle' (SA) is frequently determined using linear lead transformation matrices that require the entire 12-lead electrocardiogram (ECG). While this approach is adequate when using 12-lead ECG data that is recorded in the resting supine position, it is not optimal in monitoring applications. This is because maintaining a good quality recording of the complete 12-lead ECG in monitoring applications is difficult. In this research we assessed the differences between the 'gold standard' SA as determined using the Frank VGG and the SA as determined using different reduced lead systems (RLSs). The random error component (span of the Bland-Altman 95\% limits of agreement) of the differences between the 'gold standard' SA and the SA values based upon the different RLSs was quantified. This was performed for all 62 RLSs that can be constructed from Mason-Likar (ML) limb leads I, II and all possible precordial lead subsets that contain between one and five of the 
precordial leads V1 to V6. The RLS with the smallest lead set size that produced SA estimates of a quality similar to what is achieved using the ML 12-lead ECG was based upon ML limb leads I, II and precordial leads V1, V3 and V6. The random error component (mean [95\% confidence interval]) associated with this RLS and the ML 12 -lead ECG were found to be $40.74^{\circ}\left[35.56^{\circ} ; 49.29^{\circ}\right]$ and $39.57^{\circ}$ $\left[33.78^{\circ} ; 45.70^{\circ}\right]$ respectively. Our findings suggest that a RLS that is based upon the ML limb leads I and II and the three best precordial leads can yield SA estimates of a quality similar to what is achieved when using the complete ML 12-lead ECG.

\section{Introduction}

The spatial QRS-T angle (SA) allows for the quantification of the relationship between ventricular depolarization and ventricular repolarization. A wide SA indicates an abnormal relationship between ventricular depolarization and repolarization [1]. Previous research has established the clinical value of the SA in different applications [2-4]. The SA is a vectorcardiographic parameter and typically identified using the Frank Vectorcardiogram (VCG) [5, 6]. However, the Frank VCG is not commonly recorded in present day clinical practice.

Instead, the SA is typically obtained from VCG data that is estimated or derived from the 12-lead electrocardiogram (ECG). The derived VCG data is typically obtained using linear lead transformation matrices. Different linear lead transformation matrices that allow for the derivation of Frank VCGs from 12-lead ECG data were previously developed $[6,7]$. The Kors matrix has been 
reported to yield the most accurate estimates of the SA when standard (distal limb electrodes) 12-lead ECG data is used [8, 9]. Previous research [10] has shown that the Guldenring matrix should be used when deriving the SA from the Mason-Likar (ML) 12-lead ECG [11]. This makes the Guldenring matrix the linear lead transformation matrix of choice in applications such as ECG monitoring where ML 12-lead ECG data is frequently recorded. However, the derivation of the SA from the ML 12-lead ECG using the Guldenring matrix requires ML limb leads I and II and the precordial leads V1 to V6. This is problematic as maintaining the electrical contact of the ten electrodes that are required for the recording of the ML 12-lead ECG can be challenging in monitoring applications $[12,13]$.

Vectorcardiography is based upon the assumption that the cardiac electrical activity can be approximated by a three-dimensional vector quantity that is frequently referred to as the heart-vector [14]. The three-dimensional model of the cardiac electrical activity allows for the derivation of the Frank VCG using a minimal number of three linearly independent ECG leads [15]. This allows for the derivation of the Frank VCG using reduced lead systems (RLSs) that contain ML limb leads I, II and a subset of the six precordial leads V1 to V6.

In this research we assess the estimation performance that is achieved when deriving the SA using the ML 12-lead ECG and each of the 62 different RLSs that are based upon ML limb leads I, II and any subset of the six precordial leads V1 to V6.

\section{Material and methods}




\subsection{Body surface potential map data}

Our research utilizes previously recorded body surface potential maps (BSPMs) of 726 subjects [16]. The BSPMs were recorded from 232 subjects with left ventricular hypertrophy (LVH), 265 subjects with myocardial infarction (MI) and 229 normal subjects. Each BSPM contained ECG data of 117 thoracic leads. All thoracic leads were recorded with respect to the Wilson Central Terminal (WCT). Three distal limb electrodes that were placed on the right and left wrist and the left ankle were used to derive the WCT. The 117 thoracic leads of each BSPM were recorded using thoracic electrodes placed on 81 anterior and 36 posterior recording sites. Each of the 117 thoracic leads was represented by one average QRS-T complex. Average QRS-T complexes were generated using 15 seconds of continuous ECG data.

The thoracic electrode array that was used to record the BSPMs did not cover all body locations from which body surface potentials were required. Body surface potentials that were required for our research but were not directly recorded by the thoracic electrode array were obtained through interpolation. Interpolation was performed using a two-step interpolation procedure that has previously been described in [17]. A concise description of the interpolation procedure follows. First, body surface potentials at locations that corresponded to the locations of the 352 nodes of the Dalhousie torso model [18] were derived from the recorded BSPM data. This was achieved using a Laplacian 3D interpolation procedure. Second, linear interpolation was used to derive 
required body surface potentials that were located between the 352 nodes of the Dalhousie torso model.

Random sampling was used to partition the interpolated BSPM data into one training dataset (DTrain) and one testing dataset (DTest). Table 1 details the composition of DTrain and DTest.

TABLE 1

\subsection{Mason-Likar 12-lead ECGs and reduced ECG lead sets}

All 62 different RLSs and the ML 12-lead ECG were determined for each of the 726 subjects in the study population. First, the proximal ML limb leads were determined using the interpolated BSPM data. Second, the ML WCT was calculated using the ML limb leads. Third, the precordial leads of the ML 12-lead ECG were extracted from the BSPM data and measured with respect to the ML WCT.

\subsection{Vectorcardiographic data}

One Frank VCG was extracted for each of the 727 subjects in the study population. First, the body surface potentials at the locations of the Frank electrodes A, C, E, F, H, I and M were determined using the interpolated BSPM data. Second, the body surface potentials at the Frank electrode locations were 
used to calculate the three Frank VCG leads X, Y and Z using the previously published set of equations (1) to (3) [19].

$$
\begin{aligned}
& X=0.610 \varphi_{A}+0.171 \varphi_{C}-0.171 \varphi_{I} . \\
& Y=0.655 \varphi_{F}+0.345 \varphi_{M}-1.000 \varphi_{H} . \\
& Z=0.1333 \varphi_{A}+0.736 \varphi_{M}-0.264 \varphi_{I}-0.374 \varphi_{E}-0.231 \varphi_{C} .
\end{aligned}
$$

Where $\varphi_{A}, \varphi_{C}, \varphi_{E}, \varphi_{F}, \varphi_{H}, \varphi_{I}$ and $\varphi_{M}$ denote the body surface potentials at the location of the Frank electrodes $\mathrm{A}, \mathrm{C}, \mathrm{E}, \mathrm{F}, \mathrm{H}, \mathrm{I}$ and $\mathrm{M}$ respectively and $X, Y$ and $Z$ denote the three orthogonal Frank VCG leads.

We subsequently refer to all Frank VCGs that were obtained using (1) to (3) as 'gold standard' Frank VCGs.

\subsection{Linear lead transformation matrices}

One linear lead transformation matrix that allows for the derivation of the Frank VCG from RLS data was developed for each of the 62 different RLSs under investigation. The 62 linear lead transformation matrices were developed using the data in DTrain and multivariate linear regression as detailed in (4).

$$
\boldsymbol{A}_{i}=\left[\left(\boldsymbol{R} \boldsymbol{L} \boldsymbol{S}_{i}^{T} \cdot \boldsymbol{R} \boldsymbol{L} \boldsymbol{S}_{i}\right)^{-1} \boldsymbol{R} \boldsymbol{L} \boldsymbol{S}_{i}^{T}\right] \cdot \boldsymbol{V C G}
$$

Where $i \in\{1, \ldots, 62\}$ is an index variable that is used to indicate each of the 62 different RLSs, $\boldsymbol{A}_{\boldsymbol{i}}$ denotes the $(2+n) \times 3$ linear lead transformation matrix of the $i$-th RLS, $\boldsymbol{R} \boldsymbol{L} \boldsymbol{S}_{\boldsymbol{i}}$ denotes a $m_{\text {Train }} \times(2+n)$ matrix that contains the ECG data from 
the 545 subjects in DTrain used by the $i$-th RLS, $n \in\{1, \ldots, 5\}$ denotes the number of precordial leads that are used in $\boldsymbol{R} \boldsymbol{L} \boldsymbol{S}_{\boldsymbol{i}}, m_{\text {Train }}$ denotes the total number of QRS-T sample values in each lead and for all subjects of DTrain, $\boldsymbol{V} \boldsymbol{C} \boldsymbol{G}=$ $[\boldsymbol{X}, \boldsymbol{Y}, \boldsymbol{Z}]$ is a $m_{\text {Train }} \times 3$ matrix that contains the 'gold standard' Frank VCGs and the $m_{\text {Train }} \times 1$ vectors $\boldsymbol{X}, \boldsymbol{Y}$ and $\boldsymbol{Z}$ denote the three orthogonal Frank VCG leads.

We used the Guldenring matrix $[10,20]$ for the estimation of the Frank VCGs from the ML 12-lead ECGs. The Guldenring matrix was used as this matrix has, for ML 12-lead ECG data, previously been reported to yield estimates of the SA that are more accurate then what is achieved by the Kors matrix [10]. In addition, the Guldenring matrix has previously [20] been developed using multivariate linear regression and the data in DTrain. The Guldenring matrix is therefore identical to the transformation matrix that is obtained when using ML limb leads I, II and the precordial leads V1 to V6 of DTrain in (4).

\subsection{Spatial QRS-T angle}

Several different definitions of the SA have previously been used in research [7]. The definition of the SA that is used in our research is based upon the mean algebraic value of the QRS complex (mean spatial QRS axis) and the mean algebraic value of the $\mathrm{T}$ wave (mean spatial $\mathrm{T}$ axis) as computed from the Frank VCG using (5) and (6) respectively. The SA that is used in our research represents the angle between the mean spatial QRS axis and the mean spatial $\mathrm{T}$ axis and is determined using (7).

$$
\boldsymbol{Q R S}=\frac{1}{J_{p}-Q R S_{O N}} \sum_{n=Q R S_{O N}}^{J_{P}} \boldsymbol{V} \boldsymbol{G}(n)
$$




$$
\begin{aligned}
& \boldsymbol{T}=\frac{1}{T_{E N D}-J_{P}} \sum_{n=J_{P}}^{T_{E N D}} \boldsymbol{V C} \boldsymbol{G}(n) . \\
& S A=\arccos \left[\frac{\boldsymbol{Q R S} \cdot \boldsymbol{T}}{|\boldsymbol{Q R S}| \cdot|\boldsymbol{T}|}\right] .
\end{aligned}
$$

Where $\boldsymbol{Q R} \boldsymbol{S}$ is the $1 \times 3$ mean vector of ventricular depolarization, $\boldsymbol{T}$ denotes the $1 \times 3$ mean vector of ventricular repolarization, $Q R S_{O N}$ is the sample index of the QRS onset, $J_{P}$ denotes the sample index of the J-point, $T_{E N D}$ is the sample index associated with the end of the T wave, $n$ is the sample index variable, $\boldsymbol{V} \boldsymbol{C G}$ is a $m \times 3$ matrix containing $m$ sample values for each of the three VCG leads, $\arccos [\cdot]$ denotes the arc-cosine and $|\cdot|$ refers to the magnitude of a vector.

\subsection{Performance assessment}

An assessment of the performance that is achieved when estimating the SA using the 62 different RLSs and the ML 12-lead ECG was conducted using the data in DTest. First, the Guldenring matrix and the lead transformation matrices of the 62 different RLSs were used to derive the VCGs of the 181 subjects in DTest. This was performed using (8).

$$
V C G=L S_{i} \cdot A_{i}
$$

Where $i$ is a index variable, index values $i \in\{1, \ldots, 62\}$ are used to denote one of the RLSs and $i=63$ refers to the Guldenring matrix, $\boldsymbol{A}_{\boldsymbol{i}}$ is a $(2+n) \times 3$ linear lead transformation matrix, $\boldsymbol{L} \boldsymbol{S}_{\boldsymbol{i}}$ is a $m \times(2+n)$ matrix that contains the ECG data of the used lead system (ML 12-lead ECG or RLS) of one particular subject in 
DTest, $n \in\{1, \ldots, 6\}$ denotes the number of precordial leads that are used by the lead system, $\boldsymbol{V} \boldsymbol{C} \boldsymbol{G}=[\boldsymbol{X}, \boldsymbol{Y}, \boldsymbol{Z}]$ is a $m \times 3$ matrix that contains the derived VCG data of one particular subject in DTest, $m$ denotes the number of QRS-T sample values in each lead of the ECG data of one particular subject in DTest and the $m \times 1$ vectors $\boldsymbol{X}, \boldsymbol{Y}$ and $\boldsymbol{Z}$ denote the three orthogonal Frank VCG leads.

Second, the SA was calculated for all derived VCGs and all 'gold standard' Frank VCGs. Third, the differences between the SA values obtained from the derived VCGs and the 'gold standard' Frank VCG were calculated as detailed in (9).

$$
\Delta S A_{i}=S A_{i}-S A_{F r a n k}
$$

Where $i$ is as defined in (8), $\boldsymbol{S} \boldsymbol{A}_{\boldsymbol{i}}$ is a $1 \times 181$ vector that contains the SA values of all 181 subjects in DTest based upon VCG data that is derived using the $i$-th linear lead transformation matrix, $\boldsymbol{S} \boldsymbol{A}_{\text {Frank }}$ is a $1 \times 181$ vector that contains the SA values based upon the 'gold standard' Frank VCGs of all subjects in DTest and $\Delta \boldsymbol{S} \boldsymbol{A}_{\boldsymbol{i}}$ is a $1 \times 181$ vector that contains the estimation errors made when computing the SA based upon VCG data that is derived using the $i$-th linear lead transformation matrix.

Forth, the systematic and the random error components of the error vectors $\boldsymbol{\Delta} \boldsymbol{S} \boldsymbol{A}_{\boldsymbol{i}}$ were analyzed. The systematic error was quantified as the mean $[95 \%$ confidence interval $(\mathrm{CI})]$ of the estimation errors. We quantified the random error as the span of the Bland-Altman (BA) 95\% limits of agreement [21] as detailed in (10). 


$$
R E_{i}=2 \cdot 1.96 \cdot \operatorname{std}\left(\Delta \boldsymbol{S} \boldsymbol{A}_{i}\right)
$$

Where $R E_{i}$ denotes the magnitude of the random error component associated with the $i$-th RLS, $\operatorname{std}(\cdot)$ denotes the standard deviation and $\boldsymbol{\Delta S} \boldsymbol{A}_{\boldsymbol{i}}$ denotes one of the estimation error vectors as defined in (9).

Fifth, a Pitman-Morgan test [22] (paired, two-sided, alpha level of significance $=0.05$ ) was conducted. This test was used to test for the null hypothesis of equal random error magnitude associated with the ML 12-lead ECG and any of the 62 different RLSs. The findings of the Pitman-Morgan test were subsequently used to identify RLSs with random error components that are of similar magnitude as the random error component of the ML 12-lead ECG. Sixth, the root-meansquared differences (RMSDs) between the 'gold standard' Frank VCG leads and the derived VCG leads were calculated. The RMSD values were used to identify the contribution of the different VCG leads to the $\boldsymbol{\Delta S} \boldsymbol{A}_{\boldsymbol{i}}$ values.

\section{Results}

All RLSs under investigation were grouped in accordance to their lead set size. The RLSs in every group were sorted in accordance to the magnitude of the random error component. Figure 1 details the random error components associated with the grouped RLSs.

\section{FIGURE 1}

Figure 1. Random error of the SA and 95\% confidence interval for the random error of the SA. The random error and the 95\% confidence interval are shown 
for the 62 different RLSs and the ML 12-lead ECG. The different RLSs are grouped in accordance to their lead set. A horizontal dashed line indicates the magnitude of the random error component that is achieved when the ML 12-lead ECG is used for the derivation of the SA. Cross markers indicate RLSs that are associated with statistically significantly (paired, two-sided, Pitman-Morgan test, alpha level of significance $=0.05$ ) larger random error components when compared to what is achieved using the ML 12-lead ECG.

The best performing RLS (lowest random error component) and the worst performing RLS (highest random error component) of each lead set size were identified. Table 2 details the random error and the systematic error associated with the ML 12-lead ECG as well as for the best and the worst performing RLS of a given lead set size.

TABLE 2

Table 3 details the RMSDs between the 'gold standard' Frank VCG leads and derived VCG leads for the ML 12-lead ECG as well as for the best and the worst performing RLS of a given lead set size.

TABLE 3

The linear model in (11) was designed to assess whether the mean RMSD between the 'gold standard' Frank VCG leads and the derived VCG leads of the $i$ - 
th RLS predict the random error magnitude of the $i$-th RLS. The model in (11) was designed using bootstrapped linear regression and the data in DTest.

$$
\begin{aligned}
\dot{R E_{i}}=b_{0}+b_{x} & \left(\overline{R M S D} x_{i}-\overline{R M S D} x\right) \\
& +b_{y}\left(\overline{R M S D} y_{i}-\overline{R M S D} y\right)+b_{z}\left(\overline{R M S D} z_{i}-\overline{R M S D} z\right)
\end{aligned}
$$

Where $b_{0}, b_{x}, b_{y}$ and $b_{z}$ are the coefficients of the linear model, $\overline{R M S D} x_{i}$, $\overline{R M S D} y_{i}$ and $\overline{R M S D} z_{i}$ denote the mean RMSD between the 'gold standard' Frank VCG leads and the derived VCG leads of the $i$-th RLS, $\overline{R M S D} x, \overline{R M S D} y$ and $\overline{R M S D} z$ denote the mean RMSD between the 'gold standard' Frank VCG leads and the derived VCG leads across all RLSs under investigation.

The coefficients in (11) were developed using bootstrapped linear regression and the data in DTest. The performance of the linear model in (11) was assessed using the Pearson product-moment correlation coefficient calculated between the predicted $\left(\dot{R E_{i}}\right)$ and the actual random error magnitude $R E_{i}$ of all RLSs. The coefficient $b_{y}$ was removed from (11) as it was found not to be statistically significantly different from zero at the alpha level of 0.05 . The linear model with the remaining coefficients is provided in (12).

$$
\ddot{R E_{i}}=59.24+0.31\left(\overline{R M S D} x_{i}-\overline{R M S D} x\right)+0.47\left(\overline{R M S D} z_{i}-\overline{R M S D} z\right) .
$$

Where $\overline{R M S D} x_{i}, \overline{R M S D} x, \overline{R M S D} z_{i}$ and $\overline{R M S D} z$ is as defined in (11), $\ddot{R E} E_{i}$ refers to the predicted random error magnitude of the $i$-th RLS. 
The $95 \%$ confidence intervals of $b_{0}, b_{x}$ and $b_{z}$ were determined to be $(54.15$; 64.33), $(0.24 ; 0.38)$ and $(0.42 ; 0.51)$ respectively. The Pearson product-moment correlation coefficient (mean [95\% confidence interval]) between the predicted $\ddot{R E} E_{i}$ value and the observed $R E_{i}$ values was found to be $0.978[0.977 ; 0.979]$.

\section{Discussion}

It is possible to derive the SA using different RLSs that utilize ML limb leads I, II and any number of precordial leads. This research has shown that the quality of the derived SA is dependent upon which and how many precordial leads are used by the RLS. It was observed that the best performing RLS based upon three precordial leads was able to derive the SA with a random error magnitude that is similar $\left(\right.$ mean $=40.74^{\circ} ; 95 \%$ confidence interval $\left.=\left[35.56^{\circ} ; 49.29^{\circ}\right]\right)$ to what is achieved when using the ML 12-lead ECG (mean $=39.57^{\circ} ; 95 \%$ confidence interval $\left.=\left[33.78^{\circ} ; 45.70^{\circ}\right]\right)$

The random error magnitudes of the different RLSs that are detailed in Figure 1 are point estimates and therefore subject to sampling error. This means that the ranking of RLSs that have only small differences between their associated random error magnitudes may be subject to variation when using a different partitioning of the study population when assembling DTrain and DTest. Bootstrapping was used to quantify the effect of the sampling error on the differences in random error magnitude of adjacently ranked RLSs. The 95\% upper confidence limit of the differences in the random error magnitudes for RLSs that interchanged their rank due to the sampling error was found to be 
relatively small (mean across all adjacently ranked RLSs $=4.3^{\circ}$, standard deviation $=2.5^{\circ}$ ). This finding indicates that only adjacently ranked of RLSs with similar random error magnitudes may be subject to rank interchanges. Variations in the ranking of RLSs that may occur when using the data of different subjects in the datasets DTrain and DTest will therefore have little influence on the overall performance of specific RLSs (whether a RLS is ranked on rank 19 or rank 20 is of little practical importance provided that the random error magnitudes of both RLSs are similar).

It can be seen in Table 2 that the worst performing RLSs based upon one, two and three precordial leads lack anterior-posterior information. This is due to the absence of precordial leads V1, V2 and V3 in these RLSs. Table 3 demonstrates that the lack of this anterior-posterior information causes high estimation error levels for Frank VCG lead Z. This increased error level for Frank VCG lead Z can, based upon the linear model in (12), be identified as the source for the increased level of random error that is associated with the worst performing RLSs.

Conversely, the best performing RLSs that are based upon one, two or three precordial leads provide anterior-posterior information through the utilization of precordial leads V1 to V3.

It may seem counter intuitive that the $\overline{R M S D y}_{i}$ values were found not to contribute to the mean random error magnitude of the RLSs. However, the superior-inferior information that was used in all of the assessed RLSs was solely provided by ML limb lead II. This lead is utilized by all of the assessed RLSs. A consequence of this is a relatively low variation (standard deviation $=2.68 \mu \mathrm{V}$ ) of the $\overline{R M S D y}_{i}$ values across all assessed RLSs. This observation is in agreement with the heart-vector model of the cardiac electrical activity in accordance to 
which the precordial leads contain solely horizontal-plane information. This explains why variations of the $\overline{R M S D y}_{i}$ value are a poor predictor of the random error magnitude of any of the assessed RLSs. Nevertheless, it is speculated that the $\overline{R M S D y}_{i}$ value will be a useful predictor of (contributor to) the random error magnitude in situations where RLSs with a varying amount of superior-inferior information are compared.

\section{Conclusion}

In this paper we reported upon the SA estimation performance of all possible RLSs that are based on ML limb leads I, II and any possible combination of the six precordial leads V1 to V6.

The findings in Figure 1 and Table 2 suggest that the best performing RLS based upon three precordial leads (ML limb leads I, II and precordial leads V1, V3, and V6) can yield estimates of the SA that are as good as what is achieved when deriving the SA using the ML 12-lead ECG.

Furthermore, our findings provide guidance when deciding upon a RLS for SA monitoring applications. In addition, the findings of this research can be used to estimate the effect that the loss of precordial electrodes during a SA monitoring application might have on the quality of the derived SA values.

\section{Acknowledgements}


This work was supported in parts by the Northern Ireland Connected Health Innovation Centre, funded by the Invest Northern Ireland Competence Centre Programme and the Engineering Research Institute of the Ulster University.

\section{References}

[1] Draisma HHM, Schalij MJ, van der Wall EE, Swenne CA. Elucidation of the spatial ventricular gradient and its link with dispersion of repolarization. Heart Rhythm 2006;3(9):1092-9.

[2] de Bie MK, Koopman MG, Gaasbeek A, Dekker FW, Maan AC, Swenne CA, et al. Incremental prognostic value of an abnormal baseline spatial QRS-T angle in chronic dialysis patients. Europace 2013;15:290-6.

[3] Kardys I, Kors JA, van der Meer IM, Hofman A, van der Kuip DAM, Witteman JCM. Spatial QRS-T angle predicts cardiac death in a general population. Eur. Heart J. 2003; 24(14):1357-1364.

[4] Borleffs CJ, Scherptong RW, Man SC, van Welsenes GH, Bax JJ, van Erven L, et al. Predicting ventricular arrhythmias in patients with ischemic heart disease: clinical application of the ECG-derived QRS-T angle. Circ Arrhythm Electrophysiol 2009; 2(5):548-54.

[5] Frank E. An accurate, clinically practical system for spatial vectorcardiography. Circulation 1956;13:737-49.

[6] Kors JA, van Herpen G, Sittig AC, van Bemmel JH. Reconstruction of the Frank vectorcardiogram from standard electrocardiographic leads - diagnostic comparison of different methods. Eur Heart J 1990;11(12):1083-92.

[7] Edenbrandt L, Pahlm 0. Vectorcardiogram synthesized from a 12-lead ECG: superiority of the inverse Dower matrix. J Electrocardiol 1988;21:361-7.

[8] Cortez DL, Schlegel TT. When deriving the spatial QRS-T angle from the 12lead electrocardiogram, which transform is more Frank: regression or inverse Dower? J Electrocardiol 2010;43:302-9.

[9] Man S, Algra AM, Schreurs CA, Borleffs CJW, Scherptong RWC, van Erven L, et al. Influence of the vectorcardiogram synthesis matrix on the power of the electrocardiogram-derived spatial QRS-T angle to predict arrhythmias in patients with ischemic heart disease and systolic left ventricular dysfunction. J Electrocardiol 2011;44(0):410-5.

[10] Guldenring D, Finlay DD, Bond RR, Kennedy A, McLaughlin J, Galeotti L, Strauss DG. The derivation of the spatial QRS-T angle and the spatial ventricular gradient using the Mason-Likar 12-lead electrocardiogram. J Electrocardiol 2015;48(6):1045-1052.

[11] Mason RE, Likar I. A new system of multiple-lead exercise electrocardiography. Am Heart J 1966;71(2):196-205. 
[12] Gregg RE, Zhou SH, Lindauer JM, Field DQ, Helfenbein ED. Where do derived precordial leads fail?. J Electrocardiol 2008; 41(6):546-552.

[13] Drew BJ, Koops RR, Adams MG, Dower GE. Derived 12-lead ECG: Comparison with the standard ECG during myocardial ischemia and its potential application for continuous ST-segment monitoring?. J Electrocardiol 1994; 27(Suppl1): 249-255.

[14] Burger HC, Van Milaan JB. Heart-Vector and Leads. Br Heart J 1946; 8(3):157-161.

[15] Frank E, General Theory of Heart-Vector Projection. Circ. Res. 19544, 2(3):258-270.

[16] Montague TJ, Smith ER, Cameron DA, Rautaharju PM, Klassen GA, Felmington CS, et al. Isointegral analysis of body surface maps: surface distribution and temporal variability in normal subjects. Circulation 1981;63:1166-72.

[17] Finlay DD, Nugent CD, Nelwan SP, Bond RR, Donnelly MP, Guldenring D. Effects of electrode placement errors in the EASIderived 12-lead electrocardiogram. J Electrocardiol 2010;43:606-11.

[18] Horáček BM. Numerical model of an inhomogeneous human torso. Adv Cardiol 1974;10:51-7.

[19] Macfarlane PW, van Oosterom A, Pahlm O, Kligfield P, Janse M, Camm J. Chapter 11: lead systems. Comprehensive electrocardiology. 2nd ed. Springer; 2011. p. 375-426.

[20] Guldenring D, Finlay DD, Strauss DG, Galeotti L, Nugent CD, Donnelly MP, et al. Transformation of the Mason-Likar 12-lead electrocardiogram to the Frank vectorcardiogram. 2012 Annual International Conference of the IEEE Engineering in Medicine and Biology Society (EMBC); 2012. p. 677-80.

[21] Bland JM, Altman DG. Statistical methods for assessing agreement between two methods of clinical measurement. Lancet 1986;1:307-10.

[22] Morgan W. A test for the significance of the difference between the two variances in a sample from a normal bivariate population. Biometrika 1939:139. 


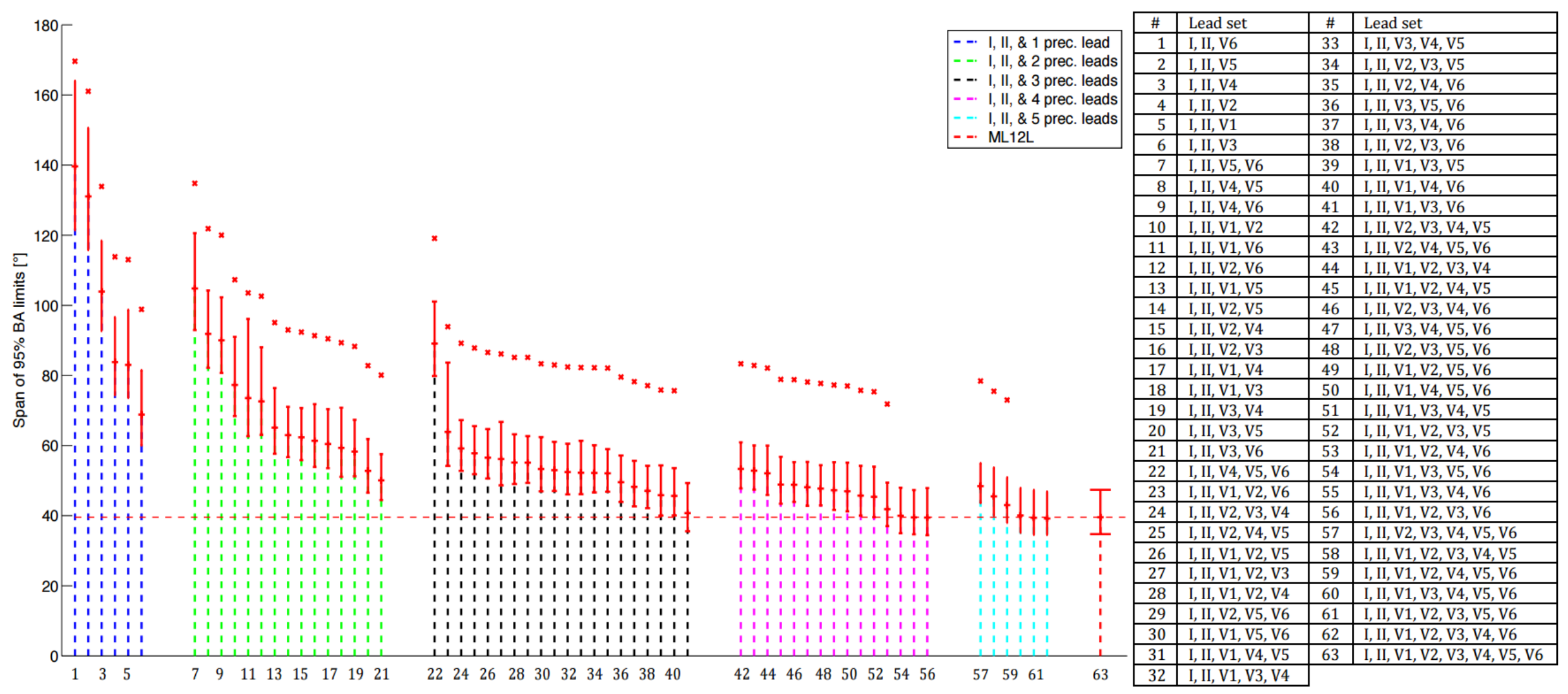

Figure 1. Random error of the SA and 95\% confidence interval for the random error of the SA. The random error and the $95 \%$ confidence interval are shown for the 62 different RLSs and the ML 12-lead ECG. The different RLSs are grouped in accordance to their lead set. A horizontal dashed line indicates the magnitude of the random error component that is achieved when the ML 12-lead ECG is used for the derivation of the SA. Cross markers indicate RLSs that are associated with statistically significantly (paired, two-sided, Pitman-Morgan test, alpha level of significance $=0.05$ ) larger random error components when compared to what is achieved using the ML 12-lead ECG. 
Table 1. Composition of test dataset (DTest) and training dataset (DTrain).

\begin{tabular}{ccccc}
\hline Dataset & \#normala & \#LVHb & \#MIc & \#totald \\
\hline DTest & 58 & 57 & 66 & 181 \\
\hline DTrain & 174 & 172 & 199 & 545 \\
\hline aNumber of normal subjects in dataset; & bNumber of subjects with LVH in dataset; \\
cNumber of subjects with MI in dataset; & dTotal number of subjects in dataset.
\end{tabular}


Table 2. Estimation performance when deriving the spatial QRS-T angle using the Mason-Likar 12-lead ECG and 62 different RLS. The random error and the systematic error for the best and the worst performing RLS of a given lead set size are provided.

\begin{tabular}{|c|c|c|c|c|}
\hline $\begin{array}{l}\text { Number of } \\
\text { precordial } \\
\text { leads used }\end{array}$ & $\begin{array}{c}\text { Lead set } \\
\text { Classification } \\
\left.\text { [Besta }{ }^{\mathrm{a}} / \text { Worst }^{\mathrm{b}}{ }^{\mathrm{b}}\right]\end{array}$ & Lead set & $\begin{array}{c}\text { Random error }\left[^{\circ}\right] \\
\text { mean }[95 \% \mathrm{CI}]^{\mathrm{c}}\end{array}$ & $\begin{array}{c}\text { Systematic error }\left[{ }^{\circ}\right] \\
\text { mean }[95 \% \mathrm{CI}]^{\mathrm{d}}\end{array}$ \\
\hline 6 & $\mathrm{~N} / \mathrm{Ae}^{\mathrm{e}}$ & I, II, V1, V2, V3, V4, V5, V6 & $39.57[33.78 ; 45.70]$ & $3.74[2.25 ; 5.17]$ \\
\hline \multirow{2}{*}{5} & Best & I, II, V1, V2, V3, V4, V6 & $39.20[33.04 ; 45.56]$ & $3.65[2.19 ; 5.09]$ \\
\hline & Worst & I, II, V2, V3, V4, V5, V6 & $48.52[43.58 ; 54.96]$ & $4.88[3.07 ; 6.68]$ \\
\hline \multirow{2}{*}{4} & Best & I, II, V1, V2, V3, V6 & $39.45[32.99 ; 45.37]$ & $2.67[1.19 ; 4.11]$ \\
\hline & Worst & I, II, V2, V3, V4, V5 & $53.34[47.73 ; 60.85]$ & $5.25[3.29 ; 7.24]$ \\
\hline \multirow{2}{*}{3} & Best & I, II, V1, V3, V6 & $40.74[35.56 ; 49.29]$ & $3.34[1.81 ; 4.83]$ \\
\hline & Worst & I, II, V4, V5, V6 & 89.10 [79.88; 101.12] & $-12.60[-15.84 ;-9.26]$ \\
\hline \multirow{2}{*}{2} & Best & I, II, V3, V6 & $50.08[43.25 ; 56.39]$ & $-0.14[-1.99 ; 1.73]$ \\
\hline & Worst & I, II, V5, V6 & $104.80[92.96 ; 120.68]$ & $-14.00[-17.78 ;-9.99]$ \\
\hline \multirow{2}{*}{1} & Best & I, II, V3 & $68.83[58.72 ; 78.74]$ & $-0.20[-2.67 ; 2.45]$ \\
\hline & Worst & I, II, V6 & 139.62 [121.57; 164.33$]$ & $-15.24[-20.21 ;-9.87]$ \\
\hline
\end{tabular}

aBest performing lead set of a given lead set size; bWorst performing lead set of a given lead set size; cBootstrapped bias- corrected and accelerated 95\% confidence intervals of the random error component, Confidence intervals of the random error component are based on 20000 bootstrap replicates; dBootstrapped bias- corrected and accelerated 95\% confidence intervals of the systematic error component, Confidence intervals of the systematic error component are based on 20000 bootstrap replicates; ${ }^{\text {Not }}$ applicable as there is only one lead set based upon the six precordial leads V1 to V6. 
Table 3. Root mean squared difference values calculated between the derived VCG leads and the 'gold standard' Frank VCG leads. Root mean squared differences are provided for the best and the worst performing RLS of a given lead set size.

\begin{tabular}{|c|c|c|c|c|c|}
\hline $\begin{array}{l}\text { Number of } \\
\text { precordial } \\
\text { leads used }\end{array}$ & $\begin{array}{c}\text { Lead set } \\
\text { Classification } \\
\left.\text { [Besta/Worst }{ }^{\mathbf{b}}\right]\end{array}$ & Lead set & $\begin{array}{c}\text { RMSD }[\mu \mathrm{V}] \text { of } \\
\text { Frank lead X } \\
\text { mean }[95 \% \mathrm{CI}]^{\mathrm{c}}\end{array}$ & $\begin{array}{c}\text { RMSD }[\mu \mathrm{V}] \text { of } \\
\text { Frank lead Y } \\
\text { mean }[95 \% \mathrm{CI}]^{\mathrm{d}}\end{array}$ & $\begin{array}{c}\text { RMSD }[\mu \mathrm{V}] \text { of } \\
\text { Frank lead Z } \\
\text { mean }[95 \% \mathrm{CI}]^{\mathrm{e}}\end{array}$ \\
\hline 6 & $\mathrm{~N} / \mathrm{A}^{\mathrm{f}}$ & I, II, V1, V2, V3, V4, V5, V6 & $34.6[31.4 ; 38.9]$ & $52.1[48.1 ; 57.7]$ & $47.1[43.3 ; 51.9]$ \\
\hline \multirow{2}{*}{5} & Best & I, II, V1, V2, V3, V4, V6 & $35.5[32.2 ; 40.1]$ & $52.8[48.8 ; 58.8]$ & $48.4[44.6 ; 53.0]$ \\
\hline & Worst & I, II, V2, V3, V4, V5, V6 & $35.4[32.0 ; 39.9]$ & $53.8[49.7 ; 59.3]$ & $69.1[64.1 ; 75.5]$ \\
\hline \multirow{2}{*}{4} & Best & I, II, V1, V2, V3, V6 & $40.1[36.4 ; 44.9]$ & $53.6[49.5 ; 59.1]$ & $52.4[48.4 ; 57.1]$ \\
\hline & Worst & I, II, V2, V3, V4, V5 & $47.8[43.5 ; 53.2]$ & $54.9[50.6 ; 60.3]$ & $74.6[69.6 ; 80.6]$ \\
\hline \multirow{2}{*}{3} & Best & I, II, V1, V3, V6 & $40.5[37.1 ; 45.0]$ & $53.3[49.1 ; 59.1]$ & $53.6[49.6 ; 58.4]$ \\
\hline & Worst & I, II, V4, V5, V6 & $35.2[31.8 ; 39.8]$ & $59.0[54.7 ; 63.9]$ & $144.8[133.0 ; 161.0]$ \\
\hline \multirow{2}{*}{2} & Best & I, II, V3, V6 & $43.1[39.6 ; 47.9]$ & $55.2[51.0 ; 60.5]$ & $79.2[73.4 ; 85.9]$ \\
\hline & Worst & I, II, V5, V6 & $37.2[33.9 ; 41.3]$ & $63.0[58.1 ; 68.9]$ & $170.6[157.6 ; 186.0]$ \\
\hline \multirow{2}{*}{1} & Best & I, II, V3 & 85.7 [78.9; 94.3] & $55.2[51.0 ; 60.4]$ & $83.4[77.4 ; 90.3]$ \\
\hline & Worst & I, II, V6 & $55.0[50.9 ; 60.1]$ & $64.3[59.2 ; 70.8]$ & $235.3[218.7 ; 254.5]$ \\
\hline
\end{tabular}

aBest performing lead set of a given lead set size; bWorst performing lead set of a given lead set size; cBootstrapped bias- corrected and accelerated 95\% confidence intervals of the root mean squared difference (RMSD) between the 'gold standard' Frank VCG lead X and the derived VCG lead X, Confidence intervals of the random error component are based on 20000 bootstrap replicates; dBootstrapped biascorrected and accelerated $95 \%$ confidence intervals of the root mean squared difference (RMSD) between the 'gold standard' Frank VCG lead Y and the derived VCG lead Y, Confidence intervals of the random error component are based on 20000 bootstrap replicates; eBootstrapped bias- corrected and accelerated 95\% confidence intervals of the root mean squared difference (RMSD) between the 'gold standard' Frank VCG lead Z and the derived VCG lead Z, Confidence intervals of the random error component are based on 20000 bootstrap replicates; fNot applicable as there is only one lead set based upon the six precordial leads V1 to V6. 
Coefficients and performance metrics of the lead transformation matrices for the 62 RLSs under investigation.

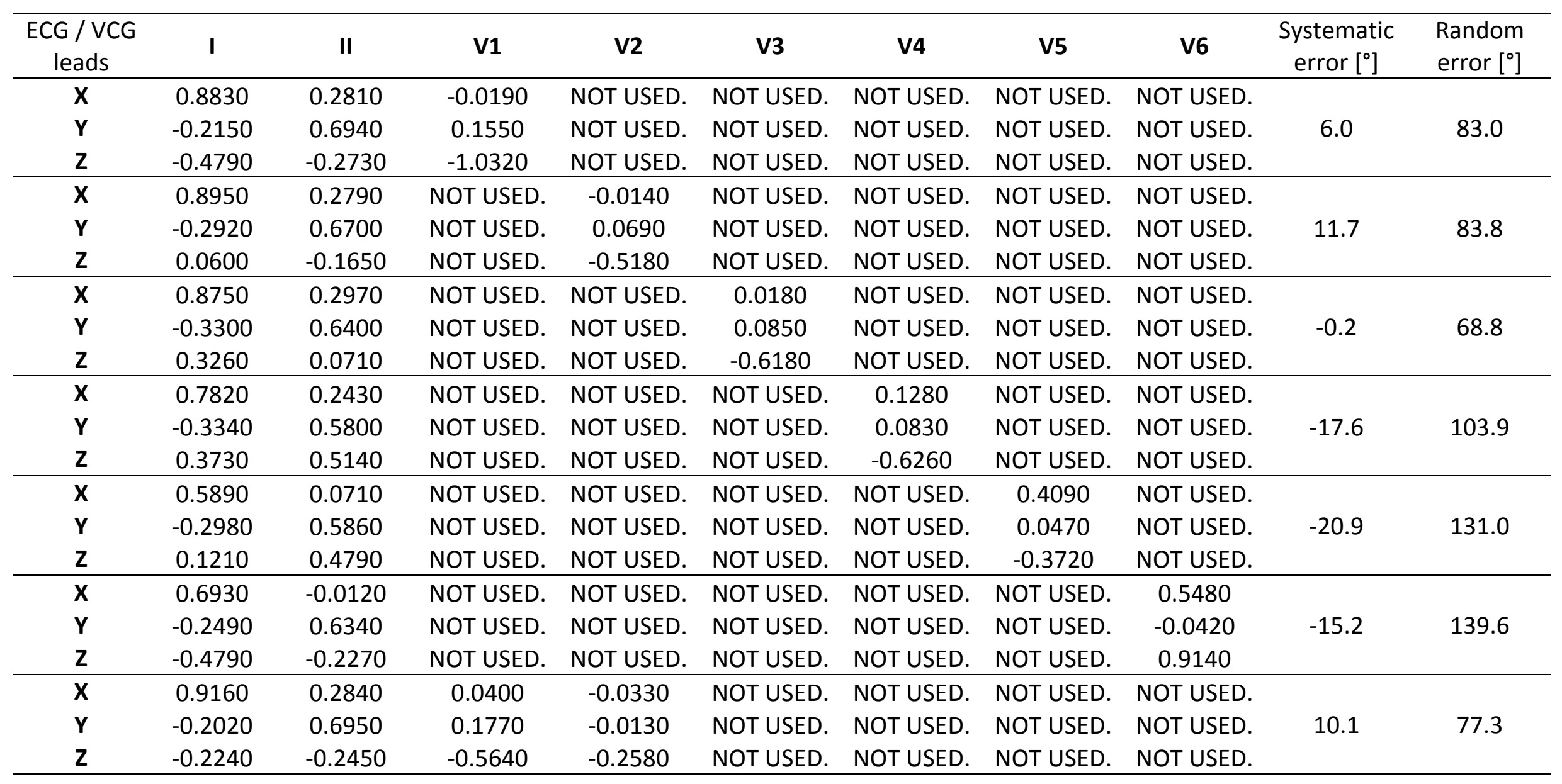




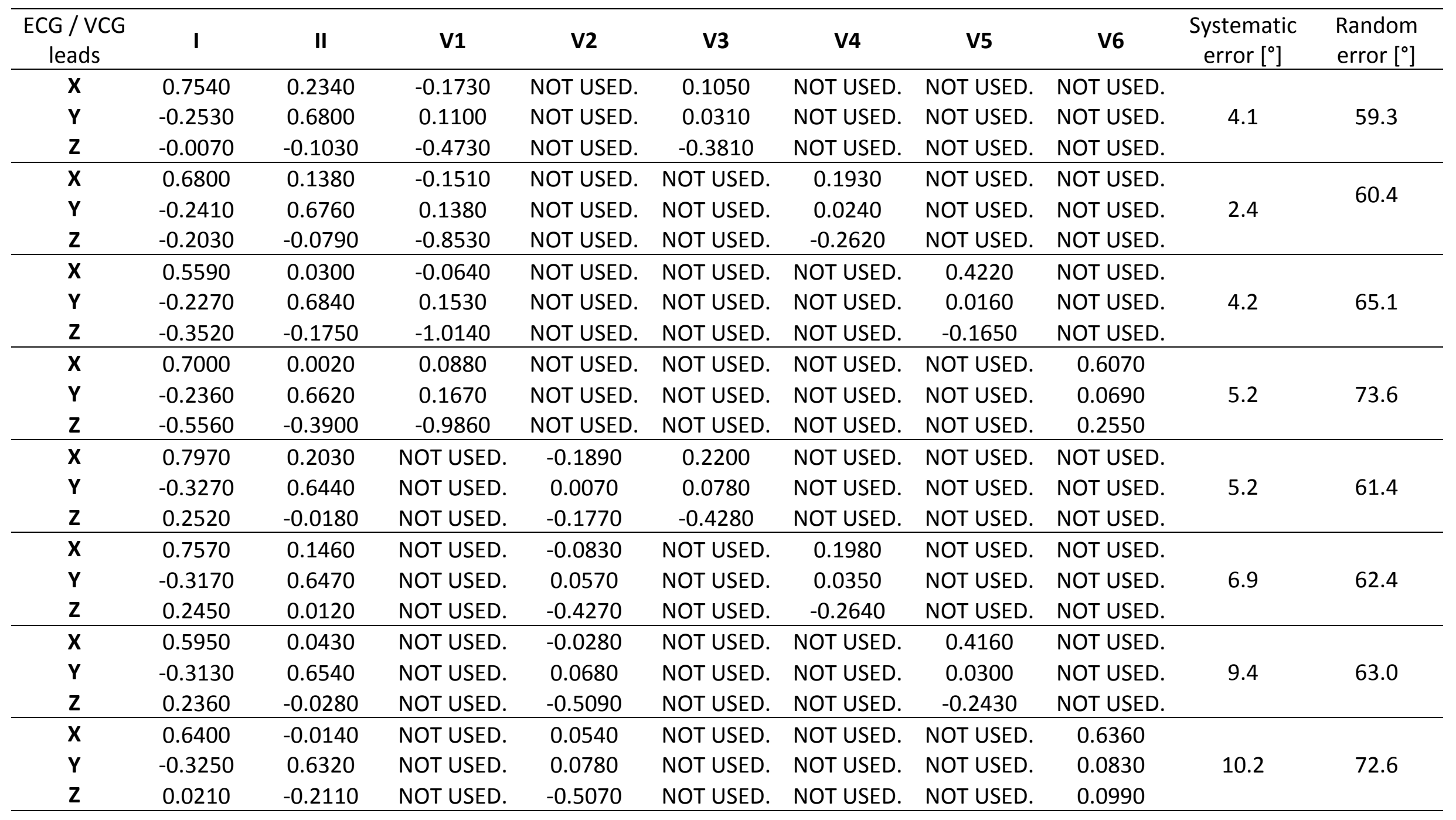




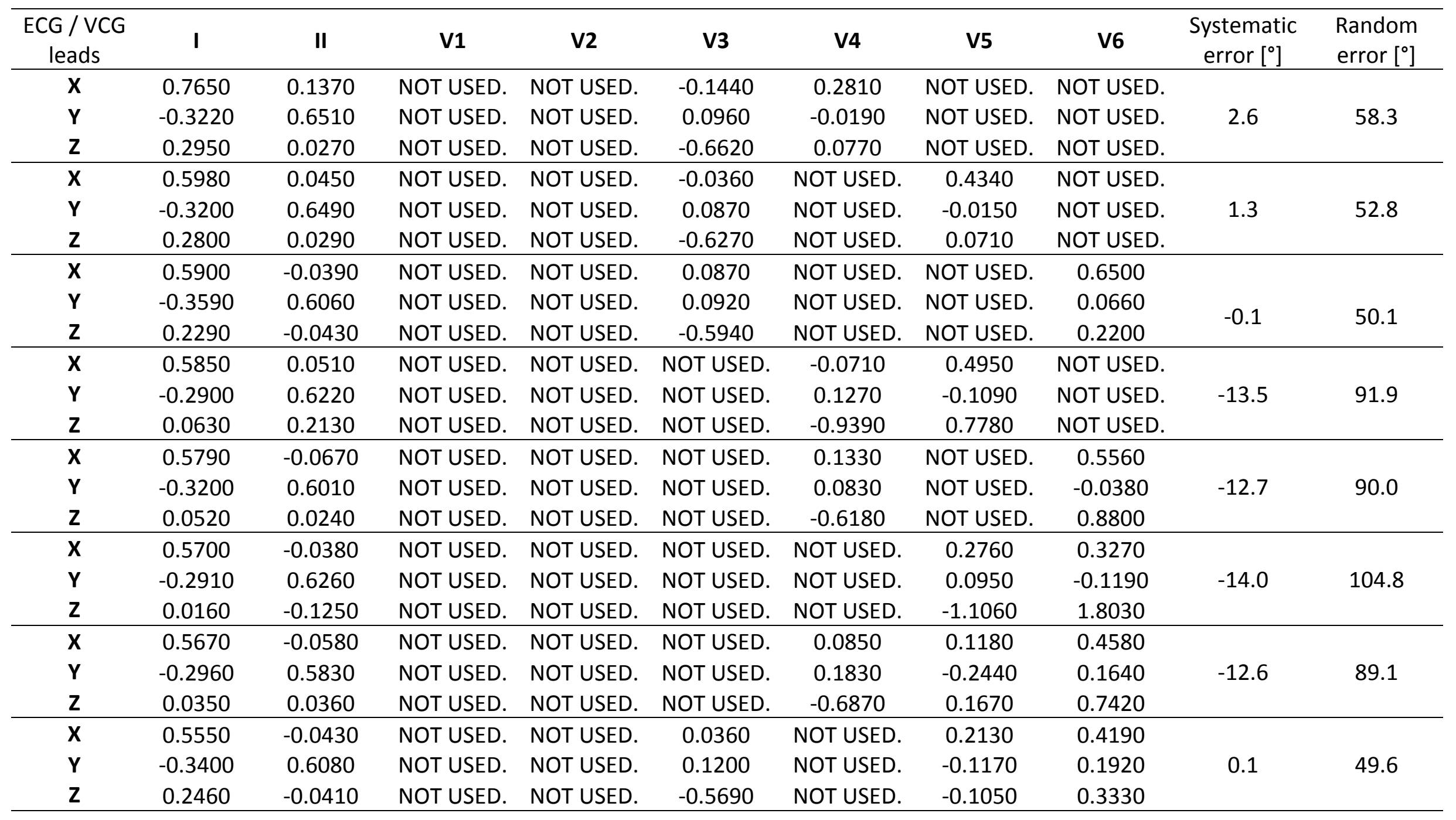




\begin{tabular}{|c|c|c|c|c|c|c|c|c|c|c|}
\hline $\begin{array}{l}\text { ECG / VCG } \\
\text { leads }\end{array}$ & $\mathbf{I}$ & II & V1 & V2 & V3 & V4 & V5 & V6 & $\begin{array}{c}\text { Systematic } \\
\text { error }\left[{ }^{\circ}\right]\end{array}$ & $\begin{array}{l}\text { Random } \\
\text { error }\left[{ }^{\circ}\right]\end{array}$ \\
\hline$Y$ & -0.3550 & 0.6150 & NOT USED. & NOT USED. & 0.1220 & -0.0450 & NOT USED. & 0.0980 & 1.0 & 48.2 \\
\hline$x$ & 0.5890 & 0.0480 & NOT USED. & NOT USED. & -0.0120 & -0.0520 & 0.4810 & NOT USED. & & \\
\hline$Y$ & -0.3240 & 0.6500 & NOT USED. & NOT USED. & 0.0980 & -0.0230 & 0.0060 & NOT USED. & 1.6 & 52.3 \\
\hline Z & 0.2930 & 0.0250 & NOT USED. & NOT USED. & -0.6600 & 0.0720 & 0.0070 & NOT USED. & & \\
\hline Z & 0.1800 & -0.1650 & NOT USED. & -0.4300 & NOT USED. & NOT USED. & -0.5250 & 0.6450 & & \\
\hline$x$ & 0.5790 & -0.0670 & NOT USED. & 0.0000 & NOT USED. & 0.1330 & NOT USED. & 0.5550 & & \\
\hline$Y$ & -0.3380 & 0.6210 & NOT USED. & 0.0670 & NOT USED. & 0.0270 & NOT USED. & 0.0670 & 5.4 & 52.1 \\
\hline Z & 0.1560 & -0.0940 & NOT USED. & -0.3860 & NOT USED. & -0.2970 & NOT USED. & 0.2780 & & \\
\hline$x$ & 0.5880 & 0.0440 & NOT USED. & -0.0120 & NOT USED. & -0.0530 & 0.4760 & NOT USED. & & \\
\hline Z & 0.1940 & -0.0870 & NOT USED. & -0.1520 & -0.4380 & NOT USED. & NOT USED. & 0.1570 & & \\
\hline$x$ & 0.5980 & 0.0450 & NOT USED. & -0.0010 & -0.0360 & NOT USED. & 0.4340 & NOT USED. & & \\
\hline$Y$ & -0.3200 & 0.6490 & NOT USED. & 0.0010 & 0.0860 & NOT USED. & -0.0140 & NOT USED. & 5.1 & 52.2 \\
\hline Z & 0.2680 & -0.0050 & NOT USED. & -0.1920 & -0.4080 & NOT USED. & -0.0340 & NOT USED. & & \\
\hline$x$ & 0.7710 & 0.1410 & NOT USED. & 0.0500 & -0.2190 & 0.3180 & NOT USED. & NOT USED. & & \\
\hline$Y$ & -0.3240 & 0.6500 & NOT USED. & -0.0150 & 0.1190 & -0.0300 & NOT USED. & NOT USED. & 6.0 & 59.2 \\
\hline Z & 0.2620 & 0.0060 & NOT USED. & -0.2680 & -0.2630 & -0.1200 & NOT USED. & NOT USED. & & \\
\hline
\end{tabular}




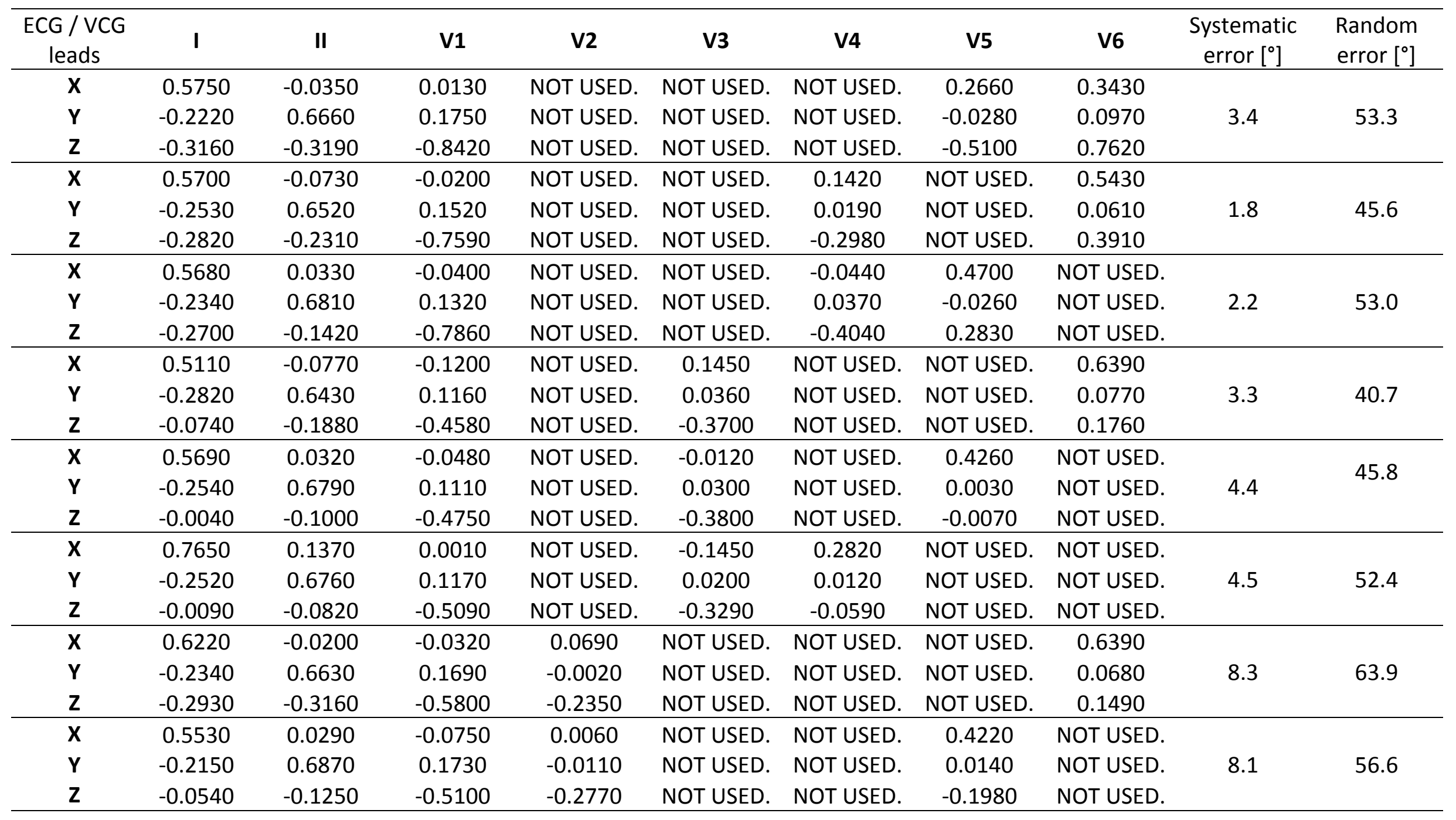




\begin{tabular}{|c|c|c|c|c|c|c|c|c|c|c|}
\hline $\begin{array}{c}\text { ECG / VCG } \\
\text { leads }\end{array}$ & 1 & II & V1 & V2 & V3 & V4 & V5 & V6 & $\begin{array}{c}\text { Systematic } \\
\text { error }\left[{ }^{\circ}\right]\end{array}$ & $\begin{array}{l}\text { Random } \\
\text { error }\left[{ }^{\circ}\right]\end{array}$ \\
\hline $\mathrm{X}$ & 0.7400 & 0.1400 & -0.0310 & -0.0690 & NOT USED. & 0.2000 & NOT USED. & NOT USED. & & \\
\hline $\mathbf{Y}$ & -0.2260 & 0.6760 & 0.1680 & -0.0170 & NOT USED. & 0.0260 & NOT USED. & NOT USED. & 6.2 & 55.1 \\
\hline $\mathbf{Z}$ & -0.0150 & -0.0720 & -0.4780 & -0.2150 & NOT USED. & -0.2390 & NOT USED. & NOT USED. & & \\
\hline$x$ & 0.7990 & 0.2040 & 0.0040 & -0.1910 & 0.2200 & NOT USED. & NOT USED. & NOT USED. & & \\
\hline $\mathbf{Y}$ & -0.2380 & 0.6700 & 0.1660 & -0.0610 & 0.0670 & NOT USED. & NOT USED. & NOT USED. & 4.3 & 56.1 \\
\hline $\mathbf{Z}$ & -0.0130 & -0.0980 & -0.4980 & 0.0280 & -0.3980 & NOT USED. & NOT USED. & NOT USED. & & \\
\hline$x$ & 0.5640 & -0.0560 & NOT USED. & NOT USED. & 0.0110 & 0.0700 & 0.1260 & 0.4630 & & \\
\hline $\mathbf{Y}$ & -0.3360 & 0.6020 & NOT USED. & NOT USED. & 0.1090 & 0.0330 & -0.1580 & 0.2130 & 1.8 & 48.1 \\
\hline $\mathbf{Z}$ & 0.2680 & -0.0760 & NOT USED. & NOT USED. & -0.6380 & 0.1920 & -0.3400 & 0.4530 & & \\
\hline$x$ & 0.5660 & -0.0570 & NOT USED. & 0.0040 & NOT USED. & 0.0810 & 0.1210 & 0.4620 & & \\
\hline $\mathbf{Y}$ & -0.3170 & 0.6050 & NOT USED. & 0.0610 & NOT USED. & 0.1120 & -0.1950 & 0.2180 & 5.7 & 52.8 \\
\hline $\mathbf{Z}$ & 0.1720 & -0.1070 & NOT USED. & -0.3910 & NOT USED. & -0.2310 & -0.1510 & 0.3950 & & \\
\hline$x$ & 0.5510 & -0.0540 & NOT USED. & -0.0410 & 0.0860 & NOT USED. & 0.1810 & 0.4370 & & \\
\hline $\mathbf{Y}$ & -0.3420 & 0.6030 & NOT USED. & -0.0170 & 0.1410 & NOT USED. & -0.1300 & 0.2000 & 4.8 & 47.7 \\
\hline $\mathbf{Z}$ & 0.2210 & -0.1040 & NOT USED. & -0.2330 & -0.2880 & NOT USED. & -0.2860 & 0.4340 & & \\
\hline$x$ & 0.5790 & -0.0670 & NOT USED. & -0.0010 & 0.0020 & 0.1320 & NOT USED. & 0.5560 & & \\
\hline $\mathbf{Y}$ & -0.3590 & 0.6120 & NOT USED. & -0.0250 & 0.1590 & -0.0640 & NOT USED. & 0.1010 & 4.8 & 48.8 \\
\hline $\mathbf{Z}$ & 0.1780 & -0.0850 & NOT USED. & -0.2900 & -0.1670 & -0.2010 & NOT USED. & 0.2420 & & \\
\hline$x$ & 0.5780 & 0.0420 & NOT USED. & -0.0450 & 0.0590 & -0.0940 & 0.4940 & NOT USED. & & \\
\hline $\mathbf{Y}$ & -0.3280 & 0.6470 & NOT USED. & -0.0170 & 0.1250 & -0.0390 & 0.0110 & NOT USED. & 5.3 & 53.3 \\
\hline $\mathbf{Z}$ & 0.2270 & -0.0120 & NOT USED. & -0.2850 & -0.2130 & -0.1940 & 0.0890 & NOT USED. & & \\
\hline$x$ & 0.5610 & -0.0630 & -0.0150 & NOT USED. & NOT USED. & 0.0930 & 0.1130 & 0.4520 & & \\
\hline $\mathbf{Y}$ & -0.2380 & 0.6340 & 0.1440 & NOT USED. & NOT USED. & 0.1040 & -0.1990 & 0.2200 & 1.9 & 47.0 \\
\hline $\mathbf{Z}$ & -0.2770 & -0.2370 & -0.7620 & NOT USED. & NOT USED. & -0.2690 & -0.0680 & 0.4450 & & \\
\hline
\end{tabular}




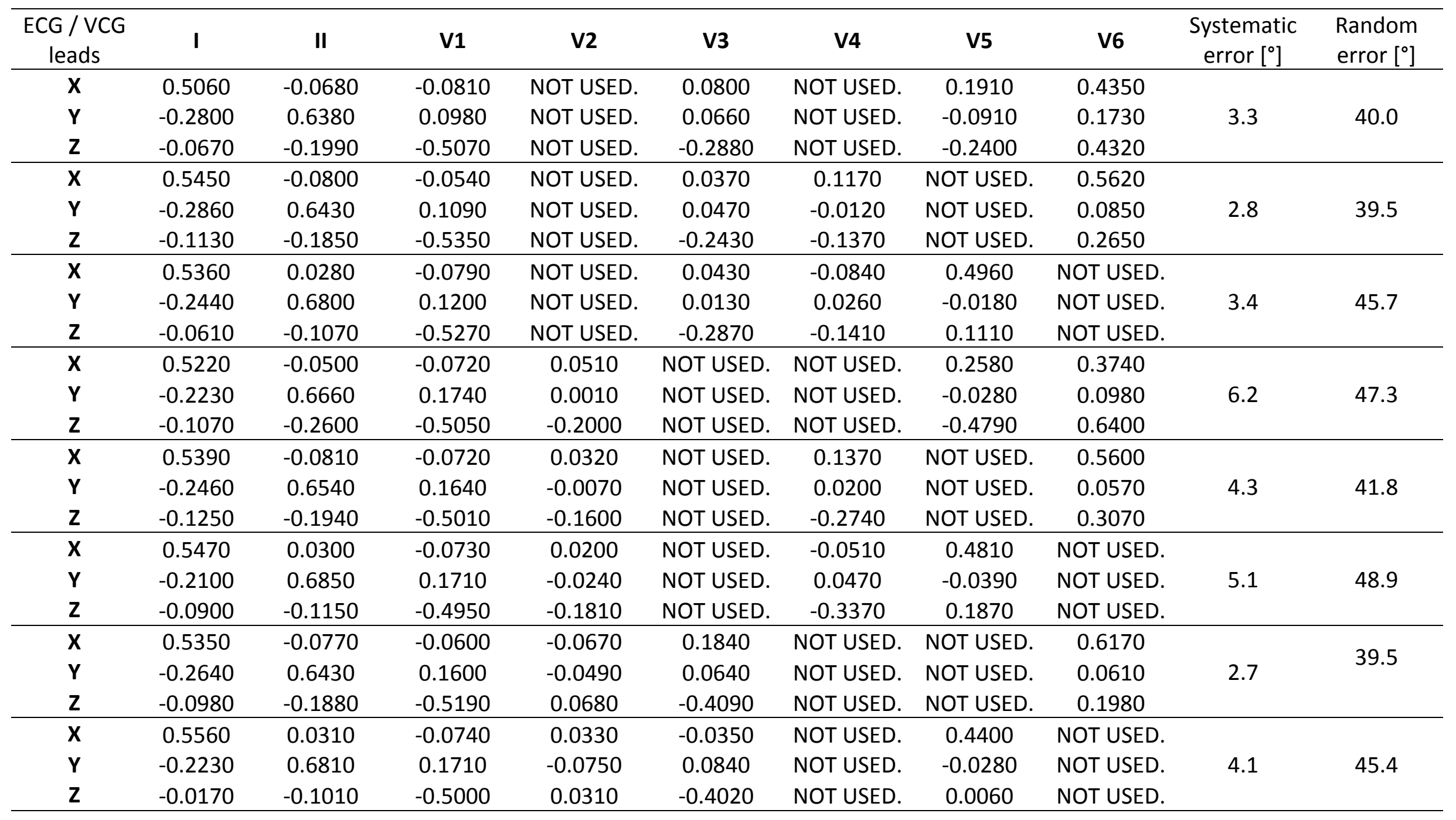




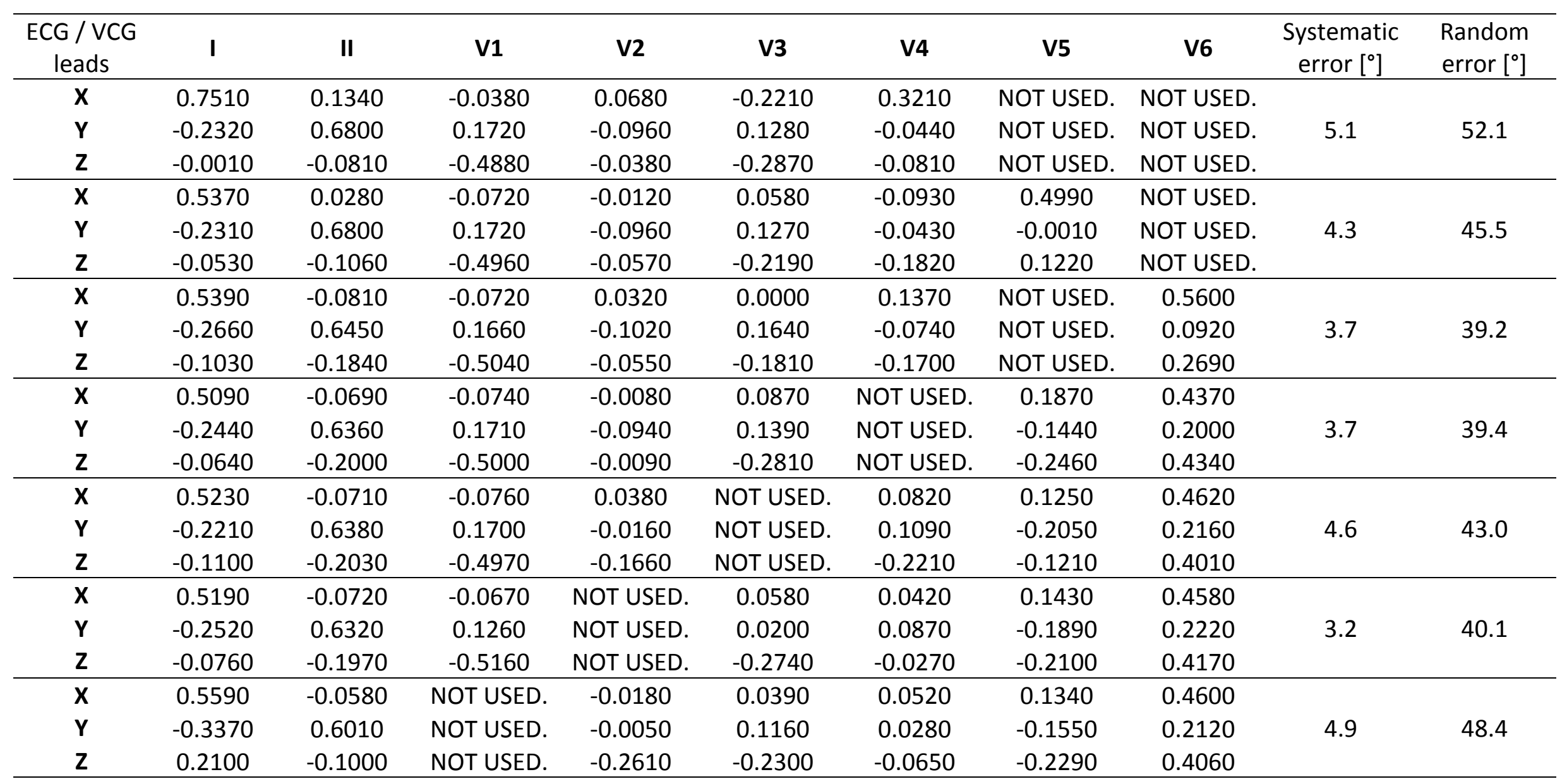

